\title{
Adjusting the Sintering Cycle of a Hadfield Sintered Steel Produced by Metal Injection Molding
}

\author{
Renan Schroeder ${ }^{a, b *}$, Antonio Itamar Ramos Filho ${ }^{a}, C_{\text {ristiano Binder }}^{a}$, Aloisio Nelmo Klein ${ }^{a}$ \\ ${ }^{a}$ Materials Laboratory, Universidade Federal de Santa Catarina-UFSC, Rua Delfino Conti, s/n, \\ Trindade, CEP 88040-370, Florianópolis, SC, Brazil \\ ${ }^{b}$ Embraco, Rua Rui Barbosa, 1020, Distrito Industrial, CEP 89219-521, Joinville, SC, Brazil
}

Received: November 9, 2014; Revised: September 6, 2015

\begin{abstract}
Processing of high manganese austenitic sintered steels present several challenges concerning thermodynamic reactions that occur during the sintering of these materials such as Mn oxidation, sublimation and even the formation of liquid phases or undesired compounds, e.g. grain boundary carbides. Therefore it is extremely important to adjust the sintering parameters to obtain the adequate microstructure and properties. In this work, the effect of some sintering parameters, i.e. temperature, gas atmosphere and cooling rate are studied by dilatometry. The experiments revealed that the sintering temperature has small impact on the microstructure formation. On the other hand, the decrease on oxygen chemical potential in the furnace atmosphere resulted in less oxidation of the powder particles. Moreover, the increasing on the cooling rate to $50{ }^{\circ} \mathrm{C} / \mathrm{min}$ avoided the formation of grain boundary carbides. As a main conclusion, a special sintering cycle for Hadfield steel samples was suggested.
\end{abstract}

Keywords: Hadfield, manganese, sintering

\section{Introduction}

High manganese austenitic steels, commonly known just by Hadfield steels, were introduced by Sir Robert Hadfield ${ }^{1}$. They are known for a good combination of strength, toughness and impact wear resistance. Despite their use in several industry sectors for a long time, the exact origin of these properties is still complex and dependent of several factors such as chemical composition, working temperature and applied stress. Nevertheless, the main explanations for the high work-hardening behavior revolve around dislocations glide, dynamic strain ageing (serrated yielding), $\varepsilon$ or $\alpha$ ' martensite transformation and twinning ${ }^{2}$.

An optimal performance of Hadfield steels is therefore dependent of occurrence of these metallurgical effects during the engineering application and, because of that, the rigid control of microstructure is of fundamental importance, thus opening good opportunities to powder metallurgy techniques. Cazzolli et al. ${ }^{3}$ also already suggested the production of Hadfield steel by powder metallurgy as an interesting alternative to eliminate machining operations frequently necessary in cast products.

Despite that, the production of sintered steels containing manganese has been a challenge along the last decades ${ }^{4}$. Looking at Ellingham's diagram for oxides, it is clear that Mn present higher thermodynamic stability compared to other more traditional elements of powder metallurgy, e.g. Ni or $\mathrm{Cu}$. This means that if $\mathrm{Mn}$ oxidizes during the sintering, its reduction becomes hardly possible at conventional sintering temperatures and, as a consequence, undesired oxides will be part of the final microstructure.

*e-mail: renan.m.schroeder@embraco.com
Ellingham`s diagram also shows that manganese oxide can be reduced only by reaction with carbon atoms, forming carbon monoxide and carbon dioxide, consequently reducing the total amount of carbon in the Hadfield alloy. Carbon deviation can lead to localized formation of martensite instead of the fully austenitic microstructure, therefore, also affecting the steel performance.

High sintering temperature may also be a problem for Mn alloys due to the high vapor pressure of $\mathrm{Mn}$, which results in sublimation of $\mathrm{Mn}$ atoms during the sintering ${ }^{5}$. The consequences are chemical deviations mainly at the parts surfaces and contamination of furnace components, like heaters, thermocouples and setter plates. Strategies to overcome this effect are based on the reduction of Mn activity in the alloy, mainly with the use of ferromanganese, master alloys or prealloyed powders rather than pure elemental $\mathrm{Mn}$ powder $^{4-6}$. The high vapor pressure of Mn also prohibits the use of vacuum furnaces which are widely used in the metal injection molding industry. The same sublimation issue can occur also for other elements, e.g. copper, as showed by Schroeder et al. ${ }^{7}$ during an investigation of plasma sintering for 17-4 PH stainless steel.

Another fact that has an important role in the microstructure formation of Hadfield alloys is the liquid phase present in the Fe-Mn-Si system. The presence of eutectic phases is dependent of localized chemical composition and sintering temperature, therefore, also related to the sintering cycle. Liquid phase in Fe-Mn-Si ternary system was first studied by $\mathrm{Salak}^{8}$ during sintering of Mn alloys.

Because of such phenomena, it is necessary to tailor correctly the sintering cycle of Hadfield steels in order 
to have the adequate final fully austenitic microstructure. In this work, the influence of temperature, gas atmosphere and cooling rate were studied before setting up the final sintering cycle.

\section{Experimental Procedure}

The alloy mixtures were prepared with commercially available powders of carbonyl iron (Sintez, grade BM), graphite (Nacional do grafite, $\mathrm{d}_{50}: 11 \mu \mathrm{m}$ ), ferrosilicon (Sandvik, Fe45Si-d ${ }_{90}: 22 \mu \mathrm{m}$ ) and ferromanganese (Chemalloy, LC $60 \times 325$ mesh) powders. They were mixed in an appropriate amount to obtain the materials presented in Table 1. The three materials without $\mathrm{Si}$ in their composition were used only to investigate the influence of each powder on the sinterability of the Hadfield steel. The powder loading was set at $92 \%$ wt, with a binder system based on polypropylene and paraffin wax.

Cylindrical specimens suitable for the dilatometric runs were injection molded in industrial conditions and debound in a two-fold route. The first extraction occurred in hexane at $50{ }^{\circ} \mathrm{C}$ during 6 hours, while the second was carried out in a plasma furnace, developed in-house and described in other works ${ }^{9,10}$. Debinding temperature did not pass $600^{\circ} \mathrm{C}$ in order to avoid excessive pre sintering already at low temperature.

Sintering was further studied in the dilatometer (Netzsch DIL 402C) and, in particular, the effects of alloying powders, sintering temperature, gas atmosphere and cooling rate, as summarized in Table 2 . Heating rate $\left(5^{\circ} \mathrm{C} / \mathrm{min}\right)$ and dwell time ( 1 hour) were kept constant in all experiments.

The first study consisted therefore of sintering the four materials described in Table 1 at $1150{ }^{\circ} \mathrm{C}$, with the goal of understanding the effect of each alloying powder on the sinterability of the Hadfield steel.

Table 1. Chemical composition of the mixtures produced in the study.

\begin{tabular}{|c|c|c|c|c|}
\hline Material & $\begin{array}{c}\mathrm{Fe} \\
(\% \mathrm{wt})\end{array}$ & $\begin{array}{c}\text { Mn } \\
(\% w t)\end{array}$ & $\begin{array}{c}C \\
(\% w t)\end{array}$ & $\begin{array}{c}\mathrm{Si} \\
(\% \mathrm{wt})\end{array}$ \\
\hline $\mathrm{Fe}$ & 100.0 & - & - & - \\
\hline $\mathrm{Fe}-12 \mathrm{Mn}$ & Bal. & 12.0 & - & - \\
\hline $\mathrm{Fe}-12 \mathrm{Mn}-1 \mathrm{C}$ & Bal. & 12.0 & 1.0 & - \\
\hline $\begin{array}{l}\text { Fe-12Mn-1C-1Si } \\
\text { (Hadfield) }\end{array}$ & Bal. & 12.0 & 1.0 & 1.0 \\
\hline
\end{tabular}

In order to analyze the effect of the sintering temperature, Hadfield steel samples were sintered also at $1200{ }^{\circ} \mathrm{C}$ and $1250{ }^{\circ} \mathrm{C}$ and compared with results at $1150{ }^{\circ} \mathrm{C}$.

The effect of gas atmosphere was addressed by changing the atmosphere composition from a mixture of $95 \%$ Argon $+5 \%$ Hydrogen to $100 \%$ Argon. These two batches were compared with a third atmosphere also composed by $95 \%$ Argon $+5 \%$ Hydrogen, however with lower oxygen chemical potential. This was achieved by passing the gas mixture into a chamber containing oxygen scavengers (Ti chips) before flowing it into the sintering chamber.

The last experiment consisted of cooling the sample after isothermal sintering at $50^{\circ} \mathrm{C} / \mathrm{min}$, which was the maximum rate achievable in the dilatometer.

After all these experiments, samples were characterized in order to understand the relations between sintering process and final microstructure and to be able to set an adequate sintering plan for Hadfield steel samples produced by metal injection molding.

\section{Results and Discussions}

\subsection{Influence of alloying powders}

Figure 1a presents the dimensional changes of the four mixtures, presented in Table 1, during heating up and isothermal holding inside the dilatomer. The horizontal axis of this graphic shows initially the temperature, associated to the heating stage and, later on, the time related to the isothermal holding.

All powder compacts expand in a very similar way up to $600{ }^{\circ} \mathrm{C}$, at which shrinkage becomes predominant over the thermal expansion. In other words, the increase in shrinkage rate is representing the effective start of sintering, which seems to be not influenced considerably by the composition of the powder compacts.

Alpha/gamma transformation, which for plain iron is found at $\approx 910^{\circ} \mathrm{C}$, occurs early for the materials containing the other alloying powders. For Fe-12Mn it is slightly shifted to $\approx 850^{\circ} \mathrm{C}$, while for $\mathrm{Fe}-12 \mathrm{Mn}-1 \mathrm{C}$ and Fe-12Mn-1C-1Si it occurs at $\approx 750{ }^{\circ} \mathrm{C}$. The shifts in transformation temperatures are due to the diffusion of $\mathrm{Mn}$ and $\mathrm{C}$ atoms in the iron lattices already at low temperature during the heating up. Silicon, which is an alpha stabilizer, seems to not influence in a great manner the $\alpha \rightarrow \gamma$ transition.

Table 2. List of tests carried out to understand the effect of alloying powders, sintering temperature, gas atmosphere and cooling rate.

\begin{tabular}{|c|c|c|c|c|}
\hline Tests & Material & Temperature & Gas atmosphere & Cooling rate \\
\hline \multirow{4}{*}{ Alloying powders } & $\mathrm{Fe}$ & \multirow{4}{*}{$1150^{\circ} \mathrm{C}$} & \multirow{4}{*}{$\begin{array}{c}95 \% \mathrm{Ar}+5 \% \mathrm{H} 2 \\
(\mathrm{Ti} \text { chips })\end{array}$} & \multirow{4}{*}{$10^{\circ} \mathrm{C} / \mathrm{min}$} \\
\hline & Fe-12Mn & & & \\
\hline & Fe-12Mn-1C & & & \\
\hline & Fe-12Mn-1C-1Si & & & \\
\hline \multirow{2}{*}{ Temperature } & \multirow{2}{*}{ Fe-12Mn-1C } & $1200^{\circ} \mathrm{C}$ & \multirow{2}{*}{$\begin{array}{c}95 \% \mathrm{Ar}+5 \% \mathrm{H} 2 \\
\text { (Ti chips) }\end{array}$} & \multirow{2}{*}{$10^{\circ} \mathrm{C} / \mathrm{min}$} \\
\hline & & $1250^{\circ} \mathrm{C}$ & & \\
\hline \multirow{2}{*}{ Gas atmosphere } & \multirow{2}{*}{$\mathrm{Fe}-12 \mathrm{Mn}-1 \mathrm{C}$} & \multirow{2}{*}{$1200^{\circ} \mathrm{C}$} & $100 \% \mathrm{Ar}$ & \multirow{2}{*}{$10^{\circ} \mathrm{C} / \mathrm{min}$} \\
\hline & & & $95 \% \mathrm{Ar}+5 \% \mathrm{H} 2$ & \\
\hline Cooling rate & Fe-12Mn-1C & $1200^{\circ} \mathrm{C}$ & $\begin{array}{c}95 \% \mathrm{Ar}+5 \% \mathrm{H} 2 \\
\text { (Ti chips) }\end{array}$ & $50^{\circ} \mathrm{C} / \mathrm{min}$ \\
\hline
\end{tabular}


Finally, during the isothermal holding, only the reduction of the sintering rate is seen, which is explained by the increase in densities.

Figure $1 \mathrm{~b}$ shows the dimensional changes occurring during the cooling. As expected, plain iron shows the $\alpha \rightarrow \gamma$ transition at $\approx 900{ }^{\circ} \mathrm{C}$; Fe-12Mn shows an inflection only at $\approx 200^{\circ} \mathrm{C}$ which in this case is associated to the transformation of the retained austenite into martensite. According to De Cooman et al. ${ }^{11}$, the complete stabilization of austenite at room temperature for the Fe-Mn system occurs only

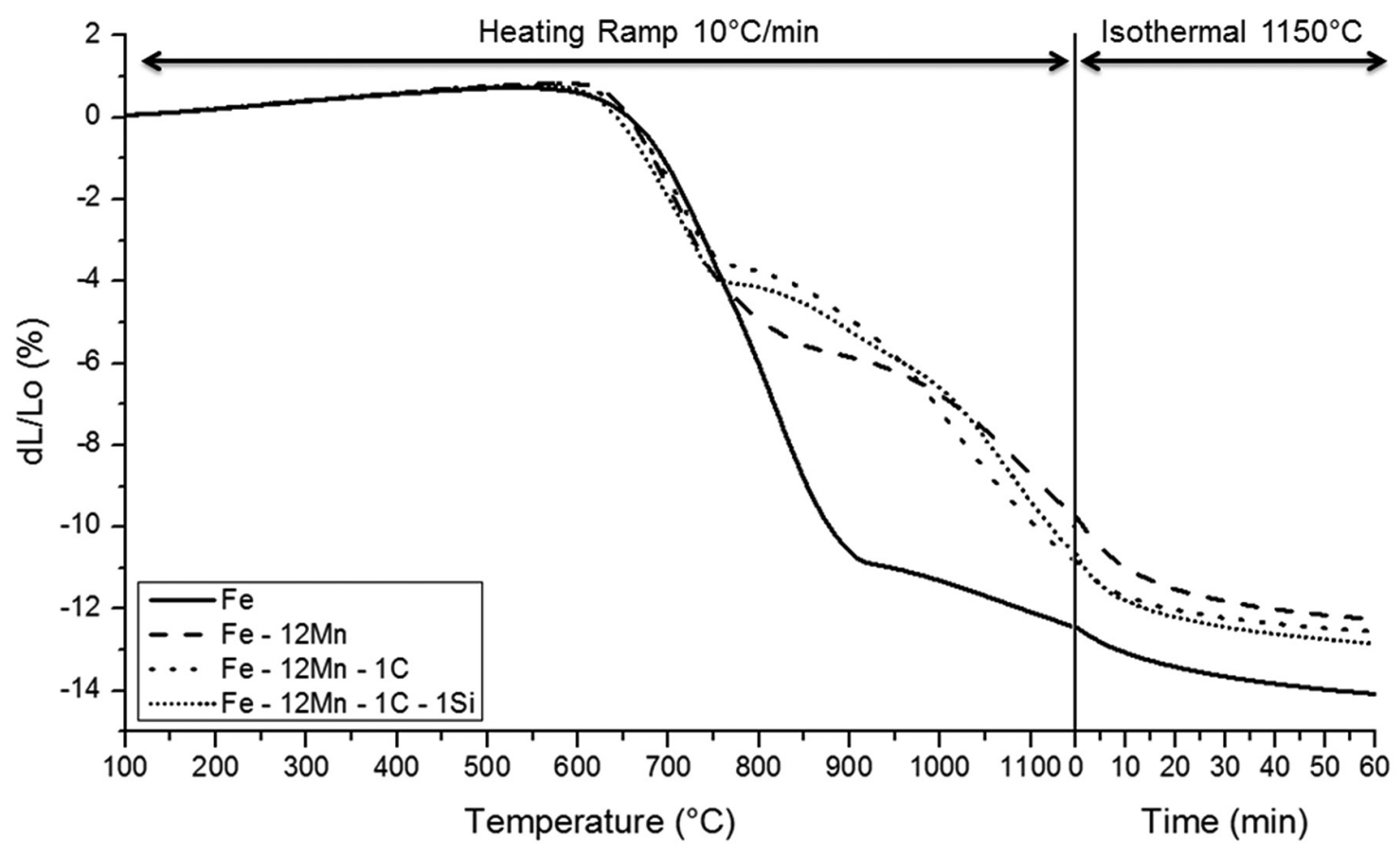

(a)

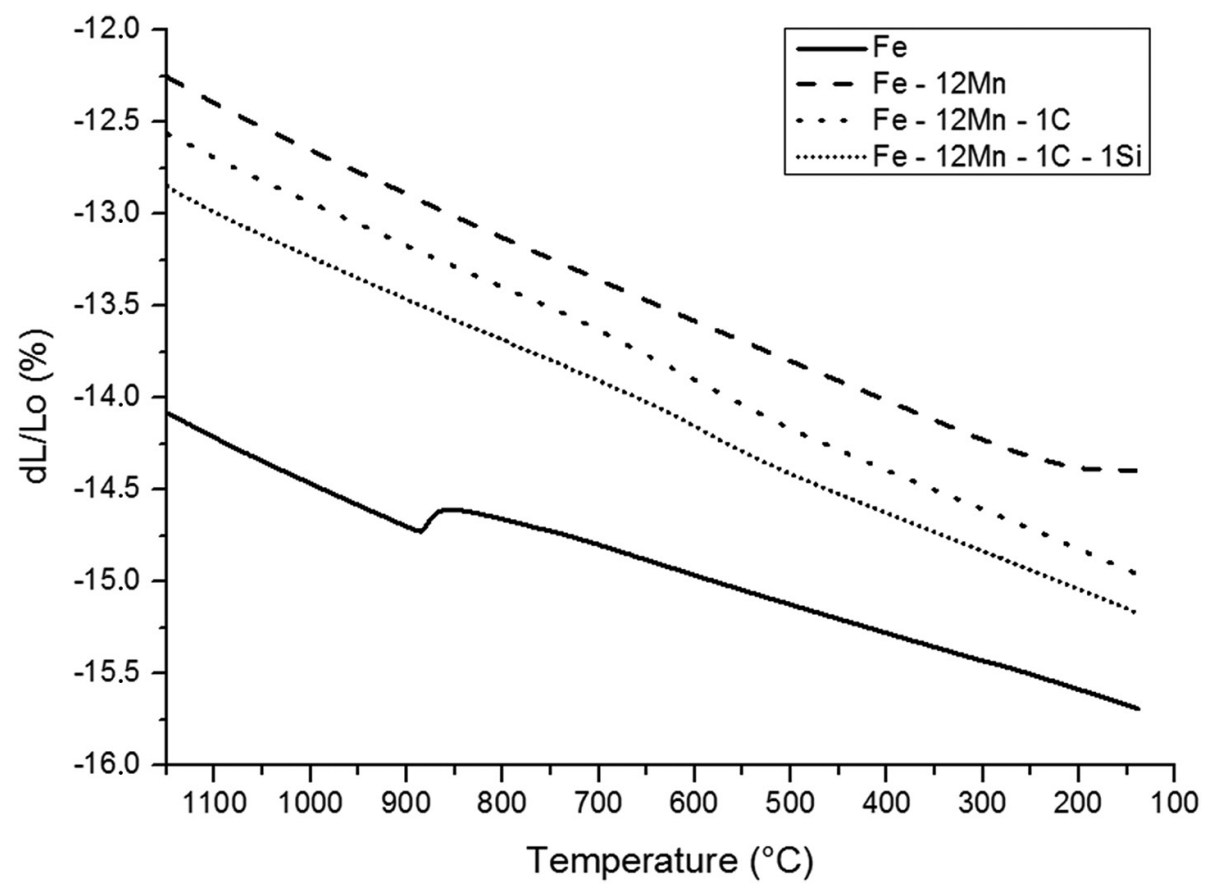

(b)

Figure 1. Dimensional changes during sintering of the materials presented in Table 1. (a) Heating and isothermal holding. (b) Cooling. Author: Renan Schroeder. 
towards at least $27 \%$ wt. of $\mathrm{Mn}$. On the other hand, both Fe$12 \mathrm{Mn}-1 \mathrm{C}$ and Fe-12Mn-1C-1Si do not present any visible phase transition during cooling, which is a good suggestion that austenite has been stabilized at room temperature.

In order to confirm those assumptions, the sintered samples were characterized in terms of standard metallography (Figure 2a-f). Plain iron presents only the expected ferrite (Figure 2a) with rounded and small pores; addition of $12 \%$ wt. of Mn changes the microstructure to martensite (Figure 2b) and also introduces larger secondary pores in the microstructure, which come from the dissolution of ferromanganese in the alloy. Furthermore, the presence of Mn-rich oxides, which were not dissolved in the matrix and now might be considered defects, are also seen in this microstructure.

In Fe-12Mn-1C (Figure 2c) and Fe-12Mn-1C-1Si (Figure 2d), it is found austenite in the core of the grains and precipitates along the grain boundaries (Figure 2e), which, probably, are carbides formed during slow cooling inside the dilatometer. Another interesting fact was that when adding $\mathrm{C}$, the Mn-rich oxides were not visible in the

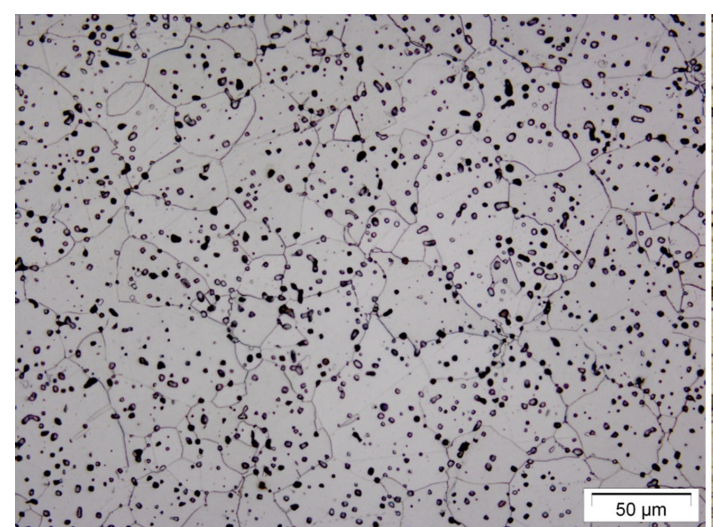

(a)

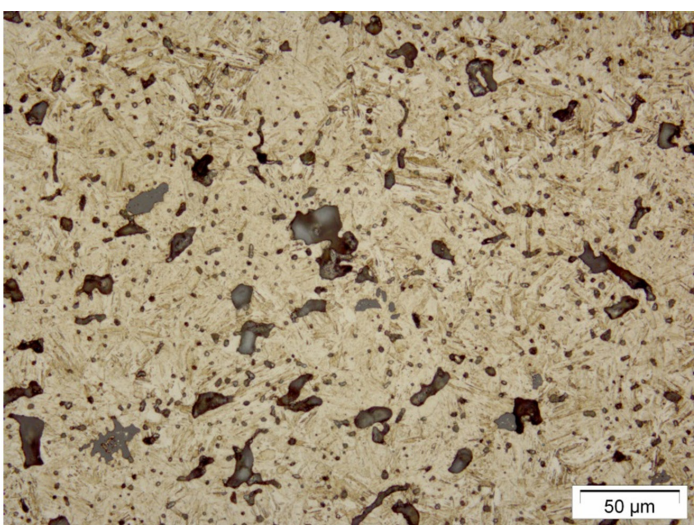

(b)

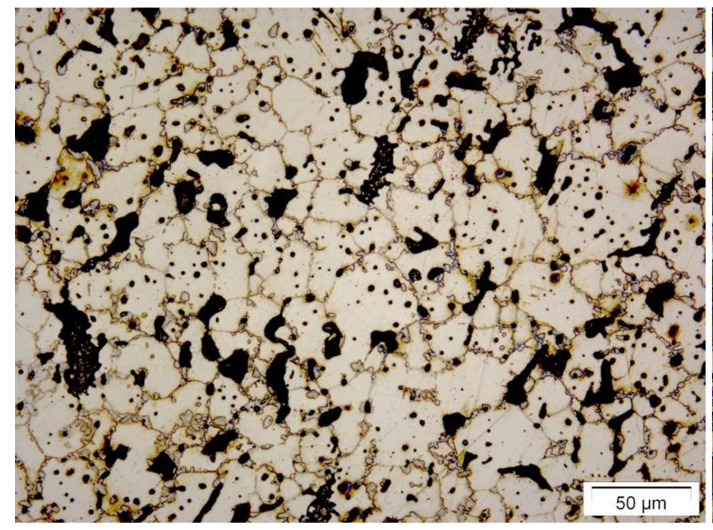

(c)

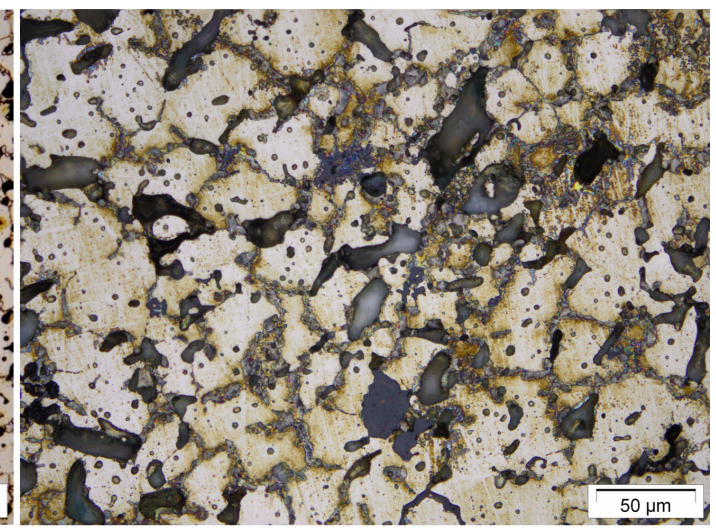

(d)

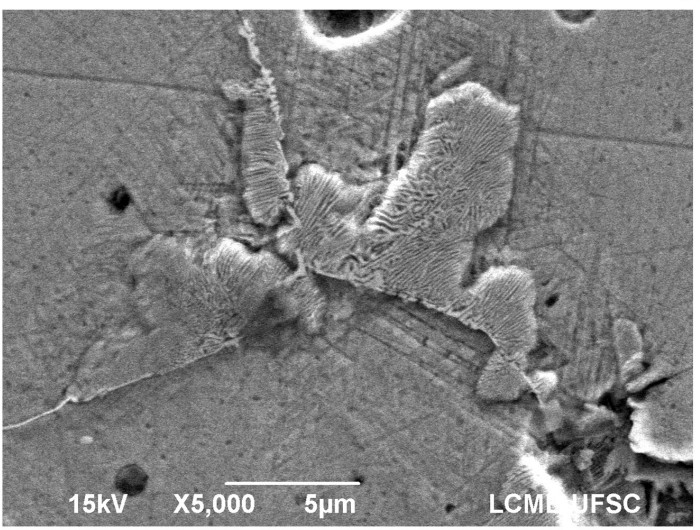

(e)

Figure 2. Microsctructural chracterization (specimen core areas) of the four materials presented in Table 1. (a) Fe. (b) Fe-12Mn. (c) Fe-12Mn-1C. (d) Fe-12Mn-1C-1Si. (e) SEM image of the precipitate formed in the Fe-Mn-C system. Author: Renan Schroeder. 
final microstructures, probably meaning that they have been minimized by carbothermal reductions.

\subsection{Influence of sintering temperature}

The first study showed mainly three problems related to the development of Hadfield steels by metal injection molding: precipitates in the grain boundary, large secondary pores and in some cases oxidation. The first problem is already elucidated in the literature ${ }^{12}$ and it is quite obvious that Hadfield samples must undergo a heat treatment such as solution annealing followed by quenching to obtain the fully austenitic microstructure. Despite knowing this necessity, this preliminary work was focused only at the MIM aspects, so heat treatments were not addressed in the current investigation.

On the other hand, the other two issues have large relation with sintering and in fact there are several possible alternatives to repair them. The first parameter to choose was the sintering temperature as it is known that when increasing it, densification (minimization of the porosity) normally can be improved and also oxidation minimized due to the lower thermodynamical stability of oxides at higher temperature.

Figure 3 shows the dimensional changes of the Hadfield samples sintered at three different temperatures during the whole sintering cycle. The curves are almost identical with only small differences in the shrinkage of the alloy sintered at $1250{ }^{\circ} \mathrm{C}$. The formation of liquid phase during sintering was surprisingly not evident in these analyses.

The microstructures, showed in Figure $4 \mathrm{a}-\mathrm{c}$, did not reveal also any significant difference among the alloys. They remained austenitic with grain boundary precipitates, and the large secondary pores were not eliminated or even minimized, but only became more rounded. Furthermore,

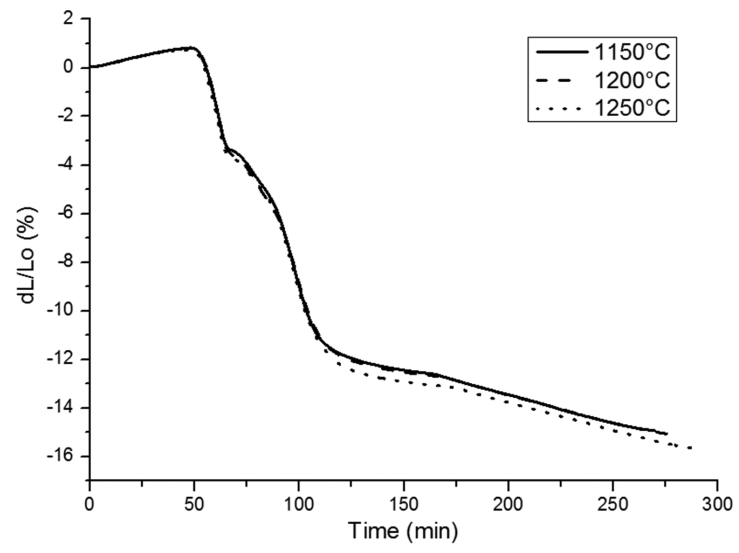

Figure 3. Dimensional changes of Hadfield samples sintered at $1150{ }^{\circ} \mathrm{C}, 1200^{\circ} \mathrm{C}$ and $1250{ }^{\circ} \mathrm{C}$. Author: Renan Schroeder.

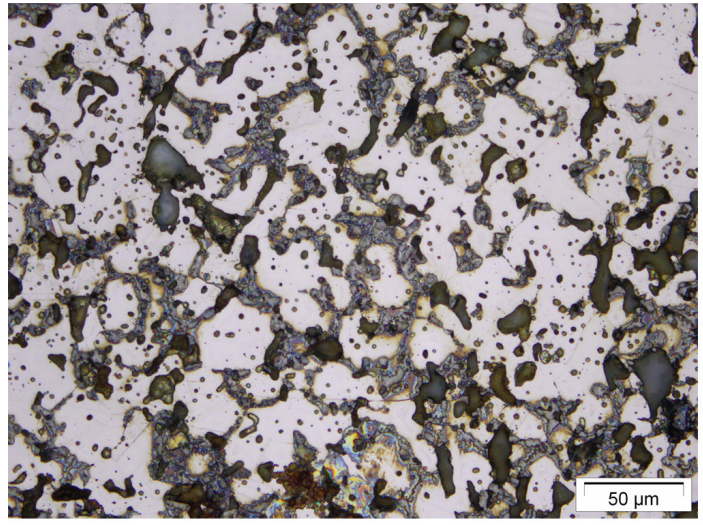

(a)

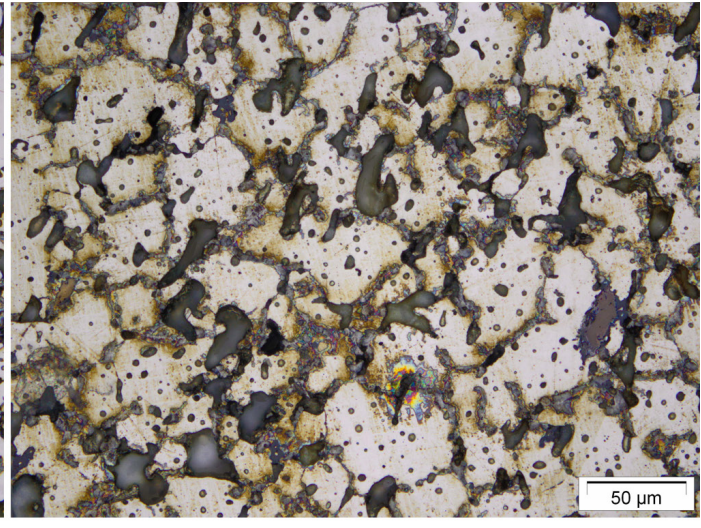

(b)

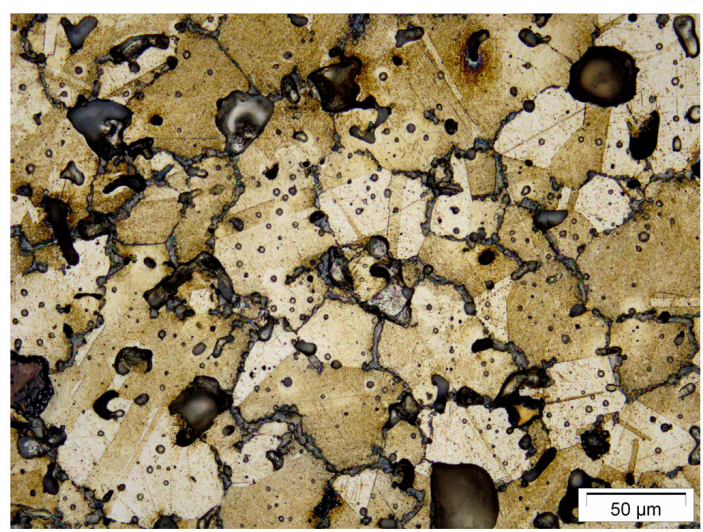

(c)

Figure 4. Microstructural characterization (core areas) of Hadfield steel sintered samples processed at $1150{ }^{\circ} \mathrm{C}(\mathrm{a}), 1200{ }^{\circ} \mathrm{C}(\mathrm{b})$ and $1250{ }^{\circ} \mathrm{C}$ (c). Author: Renan Schroeder. 
there is, to some extent, coarsening of the grains in the samples sintered at $1250{ }^{\circ} \mathrm{C}$.

It is possible to say that at least, based on these results, the sintering temperature does not have a large influence on the sinterability and microstructure formation of the Hadfield steel. Despite that, it is recommended to use low sintering temperature due to the Mn sublimation. The high porosity seems to be related to the particle size of the ferromanganese powder, which was to some extent higher than the ideal to metal injection molding.

\subsection{Influence of gas atmosphere}

Figure 5 presents the dimensional changes of the Hadfield alloys sintered in different gas atmosphere conditions. The differences start to be more intense after $\approx 1000{ }^{\circ} \mathrm{C}$, in particular for the sample sintered under $95 \% \mathrm{Ar}+5 \% \mathrm{H}_{2}$ (Ti chips). The cleaner atmosphere seems to allow this alloy to sinter faster, probably due to the absence of oxides in the powder surfaces.

When analyzed the microstructures of samples sintered in conditions without Ti chips, it is clear the presence of oxides surrounding FeSi particles, such as those in Figure 6a. EDS analysis,

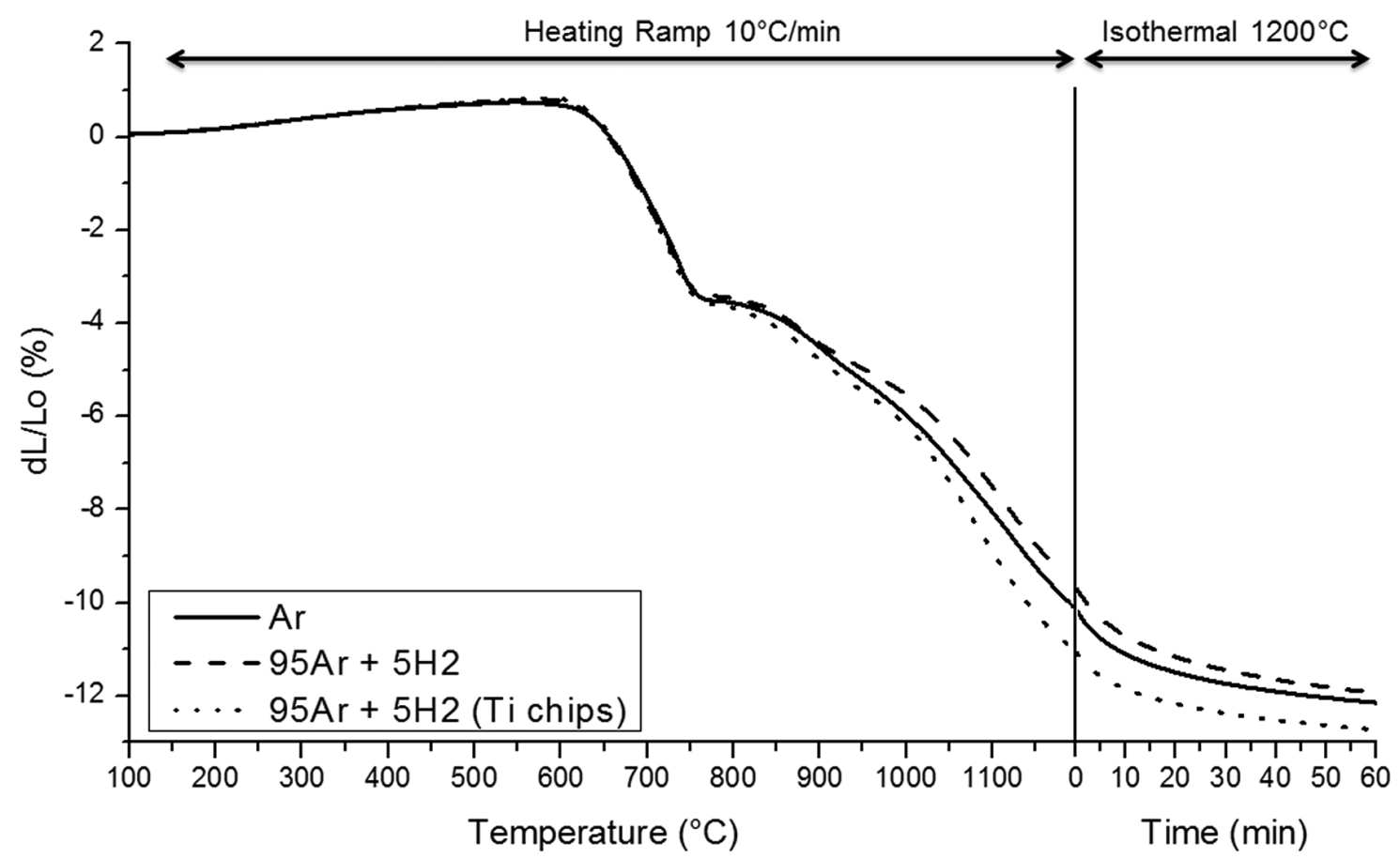

Figure 5. Hadfield steel samples sintered under different conditions of gas atmosphere. Author: Renan Schroeder.

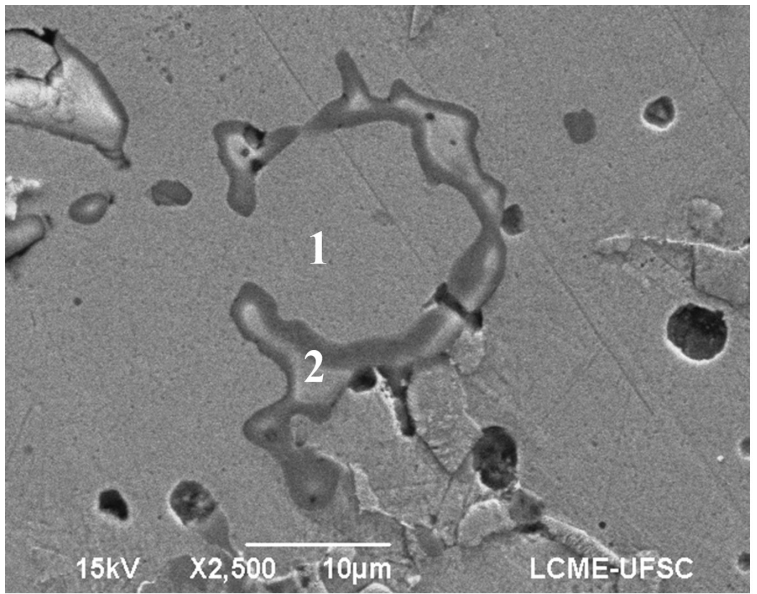

(a)
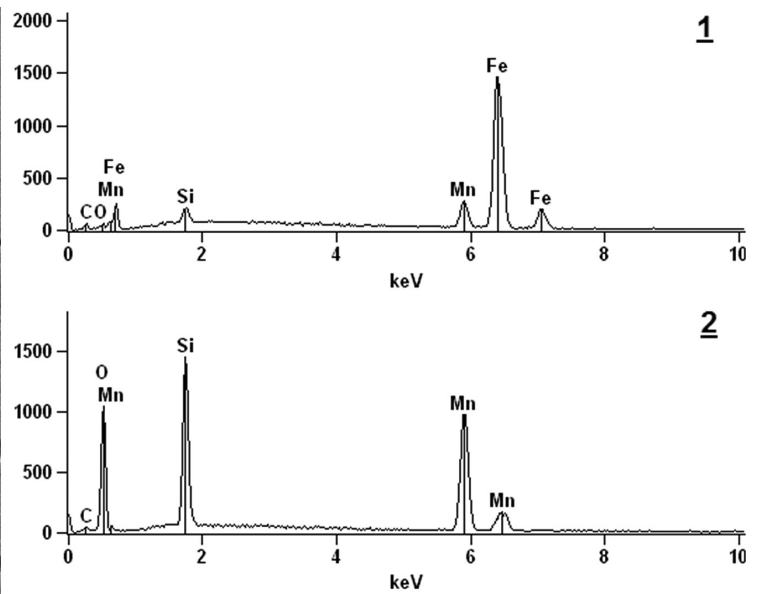

(b)

Figure 6. SEM analysis showing oxidation in atmospheres containing higher amounts of oxygen. (a) SE image. (b) EDS analyses of points 1 and 2. Author: Renan Schroeder. 


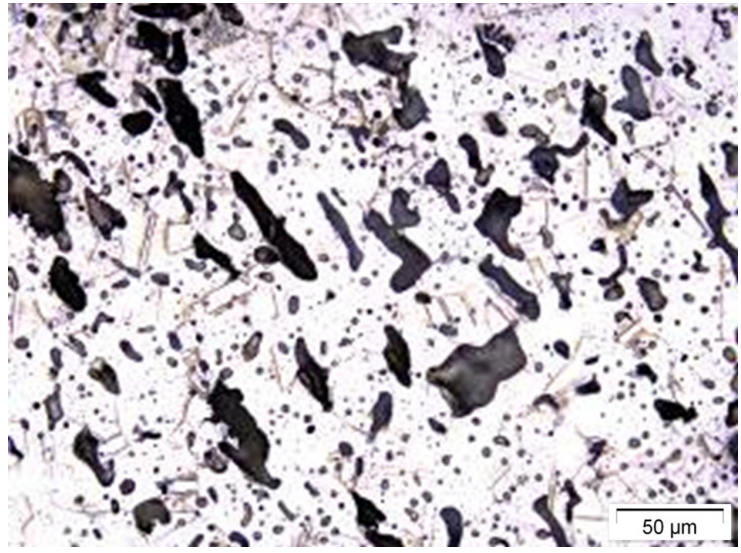

Figure 7. Microstructure of Hadfield steel sample obtained in a cycle with high cooling rate $\left(50^{\circ} \mathrm{C} / \mathrm{min}\right)$. Author: Renan Schroeder.

present in Figure 6b, confirmed that those structures have high oxygen level, therefore characterizing oxides.

Silicon has high diffusion rate in Fe-Mn system, so when it is free, i.e not oxidized, it shall induce higher shrinkage rates, exactly as observed in the diltometric results on Figure 5.

\subsection{Influence of cooling rate}

Carbides have a large tendency of precipitation in Hadfield steel microstructure during its cooling from any thermal process if not controlled properly the cooling rate, as showed in Figure 2e. Basically there are two types of carbides: thin or thick. Thinner carbides, smoothly formed in the grain boundaries, are less aggressive to the mechanical properties and, therefore, less important in the microstructure. On the other hand, thick carbides, originally formed from coarsening of thin carbides, are detrimental to the mechanical properties of the steel and must be avoided. Thick carbides

\section{References}

1. Hadfield RA. Hadfield's manganese steel. Science. 1888; 12(306):284-286. PMid:17840151.

2. Bouaziz O, Allain S, Scott CP, Cugy P and Barbier D. High manganese austenitic twinning induced plasticity steels: A review of the microstructure properties relationships. Current Opinion in Solid State and Materials Science. 2011; 15(4):141168. http://dx.doi.org/10.1016/j.cossms.2011.04.002.

3. Cazzolli M, Menapace C, Perina M and Molinari A. Microstructure and tensile properties of Hadfield steel produced by Metal Injection Moulding. In: Proceedings of the Euro PM Congress \& Exhibition; 2012; Basel. Shrewsbury: EPMA; 2012.7 p.

4. Hryha E, Dudrova and Nyborg E. Critical aspects of alloying of sintered steels with manganese. Metallurgical and Materials Transactions. A, Physical Metallurgy and Materials Science. 2010; 41(11):2880-2897. http://dx.doi.org/10.1007/s11661010-0357-5.

5. Salak A. Sintered manganese steels, part 2: manganese evaporation during Sintering. Powder Metallurgy International. $1980 ; 12: 72-75$. can be normally characterized by the presence of cementite lamellas and mixed carbides inside of an austenitic area.

Looking at the elimination or at least reduction of thick carbides, the last experiment consisted of cooling the sintering chamber at $50{ }^{\circ} \mathrm{C} / \mathrm{min}$, which was the maximum cooling rate achievable in the dilatomer. The results of the microstructure analysis, presented in Figure 7, clearly confirmed a massive reduction of carbides, which even complicated the identification of grain boundaries, due to the lower effect of etchants in these areas.

\section{Conclusions}

Processing of Hadfield steels by metal injection molding is feasible. In terms of processing conditions it is recommended:

a) Sintering temperature: $1200{ }^{\circ} \mathrm{C}$. Higher temperatures can lead to Mn sublimation, which may change superficial properties and lead to furnace deterioration, while lower temperatures may impact densification and alloy homogenization.

b) Gas atmosphere: Argon $+5 \%$ Hydrogen + oxygen scavengers, e.g. Ti chips, to reduce oxygen chemical potential. As cleaner is the atmosphere, cleaner will be the microstructure in terms of oxides.

c) Cooling rate: at least $50{ }^{\circ} \mathrm{C} / \mathrm{min}$, in order to reduce precipitation of grain boundary carbides.

\section{Acknowledgements}

The authors thank the Brazilian agencies Capes, CNPq, FAPESC, BNDES and the company Embraco for the financial support. Additionally, we thank the Laboratory of Microscopy (LCME) from our university for the SEM analysis.

6. Zhang Z and Sandström R. Fe-Mn-Si master alloy steel by powder metallurgy processing. Journal of Alloys and Compounds. 2004; 363(1-2):194-202. http://dx.doi.org/10.1016/S09258388(03)00462-6.

7. Schroeder R, Hammes G, Binder C and Klein AN. Plasma debinding and sintering of metal injection Moulded 17-4PH stainless steel. Materials Research. 2011; 14(4):564-568. http:// dx.doi.org/10.1590/S1516-14392011005000082.

8. Salak A. Manganese sublimation and carbon ferromanganese liquid phase formation during sintering of premixed manganese steels. The International Journal of Powder Metallurgy \& Powder Technology. 1980; 16(4):369-379.

9. Wendhausen PAP, Fusão D, Klein AN, Muzart JLR, Ristow W Jr and Machado R. Plasma assisted debinding and sintering: process and equipment. In: Proceedings of the PM World Congress \& Exhibition; 2004; Vienna. Shrewsbury: EPMA; 2004. p. 137-142.

10. Klein A, Cardoso RP, Pavanati HC, Binder C, Maliska AM, Hammes G, et al. DC plasma technology applied to powder metallurgy: an overview. Plasma Science and Technology. 2013; 15(1):70-81. http://dx.doi.org/10.1088/1009-0630/15/1/12. 
11. De Cooman BC, Chin KG and Kim J. High Mn TWIP steels for automotive applications. In: Chiaberge M, editor. New trends and developments in automotive system engineering. Rijeka: Intech; 2011. p. 101-128.
12. Kuyucak S, Zavadil R and Gertsman V. Heat-treatment processing of austenitic manganese steels. In: Proceedings of 66th World Foundry Congress; 2004; Istanbul. Istanbul: Tüdöksad; 2004. p. 1-16. 